\title{
Identification of Protein Markers Specific for Papillary Renal Cell Carcinoma Using Imaging Mass Spectrometry
}

\author{
Chan Hyun $\mathrm{Na}^{1,2,5}$, Ji Hye Hong ${ }^{1,25}$, Wan Sup Kim ${ }^{3}$, Selina Rahman Shanta ${ }^{1,2}$, Joo Yong Bang ${ }^{1,2}$, \\ Dongmin Park', Hark Kyun Kim ${ }^{4}$, and Kwang Pyo Kim ${ }^{1,2, *}$
}

Since the emergence of proteomics methods, many proteins specific for renal cell carcinoma (RCC) have been identified. Despite their usefulness for the specific diagnosis of RCC, such proteins do not provide spatial information on the diseased tissue. Therefore, the identification of cancerspecific proteins that include information on their specific location is needed. Recently, matrix-assisted laser desorption ionization (MALDI) mass spectrometry (MS) based imaging mass spectrometry (IMS) has emerged as a new tool for the analysis of spatial distribution as well as identification of either proteins or small molecules in tissues. In this report, surgical tissue sections of papillary RCC were analyzed using MALDI-IMS. Statistical analysis revealed several discriminative cancer-specific $\mathrm{m} / \mathrm{z}$-species between normal and diseased tissues. Among these $\mathrm{m} / \mathrm{z}$-species, two particular proteins, S100A11 and ferritin light chain, which are specific for papillary RCC cancer regions, were successfully identified using LC-MS/MS following protein extraction from independent RCC samples. The expressions of S100A11 and ferritin light chain were further validated by immunohistochemistry of human tissues and tissue microarrays (TMAs) of RCC. In conclusion, MALDI-IMS followed by LCMS/MS analysis in human tissue identified that S100A11 and ferritin light chain are differentially expressed proteins in papillary RCC cancer regions.

\section{INTRODUCTION}

Renal cell carcinoma (RCC) is an adverse malignancy, accounting for more than $80 \%$ of kidney neoplasms (Motzer et al.,

${ }^{1}$ Department of Applied Chemistry, ${ }^{2}$ The Institute of Natural Science, College of Applied Sciences, Kyung Hee University, Yongin 446-701, Korea, ${ }^{3}$ Department of Pathology, Konkuk University School of Medicine, Seoul 143-701, Korea, ${ }^{4}$ National Cancer Center, Goyang, 410-769, Korea, ${ }^{5}$ These authors contributed equally to this work.

*Correspondence: kimkp@khu.ac.kr

Received 19 January, 2015; revised 23 March, 2015; accepted 3 April, 2015; published online 10 June, 2015

Keywords: biomarker, LC-MS/MS, MALDI IMS, MALDI TOF, papillary renal cell carcinoma, proteomic analysis
1996). RCC is classified into three main types, such as conventional (or clear cell), papillary and chromophobe RCC. Papillary RCC has a survival rate lower than other types of RCCs (Ljungberg, 2004).

Recently, conventional imaging techniques have begun to be widely used for routine check-ups and follow-up of RCC at early stages. However, most of the conventional imaging techniques alone cannot distinguish between solid and cystic renal lesions or solid renal benign and malignant masses (Bosso et al., 2008). As there are several different types of RCCs with different survival rates, specific biomarkers are mandatory for early detection and monitoring of recurrence and response to treatment (Siu et al., 2009).

Since the advent of proteomics technologies, many attempts have been made to discover cancer-specific proteins at the proteome level, and numerous proteins have been identified (Seliger et al., 2007). However, conventional proteomics approaches cannot provide spatial information, especially when the boundary between cancer and normal tissue is not clear or when the separation of cancer tissue from normal tissue is difficult.

Recently, with the emergence of imaging mass spectrometry (IMS), it is possible to combine conventional proteomic techniques with IMS to determine protein identification as well as spatial information (Chaurand et al., 2002; 2005; Francese et al., 2009; Stoeckli et al., 2001). MALDI-IMS is based on MALDI-TOF technology, where tissue samples can be analyzed directly with the aid of different matrices. Tissue sections are placed on a conductive surface such as a gold plate or indium tin oxide (ITO)-coated glass slide and analyzed spot-byspot using MALDI-TOF. Using all the spectral data from each spot, intensities of a specific peak or certain $\mathrm{m} / \mathrm{z}$ value can be displayed by color intensity, and the spatial information of the specific peak in the tissue can be displayed (Chaurand et al., 2005; Francese et al., 2009). As a successful application of MALDI-IMS to identify peptide signatures for clear cell RCC (ccRCC) from in situ trypsin-treated tissues, Morgan et al. (2013) identified tryptic peptides corresponding to vimentin, alpha-enolase and histone $2 \mathrm{~A}$ as potential peptide signatures of ccRCC.

In this report, papillary RCC sections were prepared from frozen tissue and analyzed spot-by-spot with MALDI-MS for IMS. Cancer-specific regions were identified by Principal Component Analysis (PCA), and cancer-specific $m / z$-species were selected

eISSN: 0219-1032

(C) The Korean Society for Molecular and Cellular Biology. All rights reserved.

(c) This is an open-access article distributed under the terms of the Creative Commons Attribution-NonCommercial-ShareAlike 3.0 Unported License. To view a copy of this license, visit http://creativecommons.org/licenses/by-nc-sa/3.0/. 
by PCA and manual comparison of peaks between normal and cancerous regions. Cancer-specific proteins were further identified by LC-electrospray ionization (ESI)-tandem mass spectrometry (MS/MS) following extensive protein fractionation with high-performance liquid chromatography (HPLC). The proteins were identified following trypsin digestion of appropriate fractions and analysis on liquid chromatography mass spectrometry (LC-MS). Among them, two well-known proteins, S100A11 and ferritin light chain, were identified with high confidence. S100A11 is known to be related to colorectal cancer progression (Wang et al., 2008), tumor suppressor genes (Ohuchida et al., 2006), and prostate cancer (Rehman et al., 2004). Ferritin light chain is found in high concentration in the blood of patients with renal cell carcinoma (Essen et al., 1991; Kirkali et al., 1999; Miyata et al., 2001; Ozen et al., 1995; Singh et al., 2005). While there have been significant efforts based on MALDI-IMS to characterize biomarkers or peptide signatures in renal cancer carcinomas (Morgan et al., 2013; Steurer et al., 2014), the clinical significance of S100A11 and ferritin light chain has not been well investigated.

In this study, we successfully visualized and identified overexpression of S100A11 and ferritin light chain in papillary RCC region through combined use of MALDI-IMS and LC-ESIMS/MS. The expression of S100A11 and ferritin light chain in tissue sections of RCC was confirmed by immunohistochemistry (IHC). Combined use of MALDI-IMS and LC-ESI-MS/MS would be beneficial to develop novel histological biomarkers or protein signatures to differentiate a different subtype of RCCs.

\section{MATERIALS AND METHODS}

Materials

HPLC grade acetonitrile (ACN) and isopropanol were purchased from B\&J (USA); Trifluoroacetic acid (TFA) was from Pierce (USA). Sinapinic acid (3,5-dimethoxy-4-hydroxycinnamic acid, SA, 98\% purity) was purchased from Sigma (USA). Indium Teen Oxide (ITO)-coated glass slides were purchased from Bruker Daltonics (Germany); optimum cutting temperature (OCT) compound was from Sakura Finetek (USA). Protease inhibitor mixture was purchased from Roche (USA).

\section{Tissue samples}

Papillary RCC tissue samples $(n=4)$ were obtained, with informed consent and institutional review board (IRB) approval, from two RCC patients undergoing surgery at Konkuk University Hospital and two RCC patients undergoing surgery at the National Cancer Center in Korea (Table 1). The classification, nuclear grade and tumor stage of the renal cell carcinomas were determined according to the criteria proposed by Fuhrman et al. (Fuhrman et al., 1982), as shown in Table 1. MALDI MS and immunohistochemical analyses were performed for two retrospective surgical tissue samples, respectively.

\section{Tissue sectioning for MALDI-IMS}

Thin tissue sections $(10 \mu \mathrm{m})$ were typically cut at $-20^{\circ} \mathrm{C}$ in a cryostat and thaw-mounted onto a conductive glass slide using a procedure described by Chaurand et al. (2006). The tissue samples were maintained with the desired orientation on the cutting block using a medium such as Optimum Cutting Temperature (OCT) polymer. Before matrix application, the sections were dried for $30 \mathrm{~min}$ in desiccators. Tissue sections fixed on conductive plates were rinsed with $70 \%$ isopropanol for $30 \mathrm{~s}$ and then with $95 \%$ isopropanol for $30 \mathrm{~s}$ (Andersson et al., 2008; Chaurand et al., 2006). After washing with isopropanol, the
Table 1. Clinical characteristics of the patients

\begin{tabular}{cccc}
\hline Sex & Age & Stage & Fuhrman's (Nuclear) Grade \\
\hline M & 46 & $\mathrm{I}$ & $3 / 4$ High grade \\
M & 47 & $\mathrm{I}$ & $3 / 4$ High grade \\
M & 58 & $\mathrm{I}$ & $2 / 4$ Low grade \\
M & 42 & $\mathrm{I}$ & $1 / 4$ Low grade \\
\hline
\end{tabular}

tissue sections were dried for $30 \mathrm{~min}$ in desiccators.

SA matrix at a concentration of $10 \mathrm{mg} / \mathrm{ml}$ in $60 \%$ ACN, $40 \%$ water, and $0.2 \%$ TFA was deposited on the dried tissue sections mounted on ITO slides either using an ImagePrep (Bruker Daltonics, Germany) or Portrait 630 acoustic reagent multispotter (ARM, Labcyte Inc, USA)

\section{Protein IMS on surgical tissue sections}

MALDI spectra were acquired in positive mode with a Bruker Daltonics Autoflex III MALDI time-of-flight mass spectrometer equipped with smart beam laser technology (Germany). MS data acquisition was performed by averaging signals from 500 consecutive laser shots with a frequency of $200 \mathrm{~Hz}$. MALDITOF was operated in linear mode with delayed extraction conditions of $200 \mathrm{~ns}$. The MS data were acquired with an $\mathrm{m} / \mathrm{z}$ range between 2000 and 40,000. Before acquisition, the spectra were calibrated using protein calibration standard I at an $\mathrm{m} / \mathrm{z}$ range from 5734.56 to 16952.55 . The spatial resolution of all the mass images shown in this work was $200 \mu \mathrm{m}$. The total spectra obtained were baseline subtracted.

The distribution of obtained MS data was also analyzed statistically by principal component analysis (PCA) and classification methods. PCA for total MS spectra was performed from each group using ClinProTools v2.2 (Bruker Daltonics). Region of interest-1 (ROI-1) was selected in the normal region for PCA while ROI-2 was selected in the papillary RCC region of the tissue. We compared ROI-1 and ROI-2 to show significant differences in protein distribution between the two regions. Differences between groups were tested for statistical significance using Student's $t$-test or analysis of variance. The statistical significance was set at $p<0.05$. Ion intensities for each $\mathrm{m} / \mathrm{z}$ value were normalized with ClinPro Tools and Fleximaging software. Normalization was performed by dividing all spectral intensities by the obtained total ion count. Ion intensities were evaluated by comparing ion pairs from RCC and normal regions on the same tissue section after normalization.

Identification of proteins following extraction and separation Identification of proteins was performed using an MALDI-IMSdirected approach. After MALDI-IMS analysis, the same tissue sample was homogenized on ice, followed by sonication and centrifugation at $1000 \mathrm{~g}$ for $10 \mathrm{~min}$ at $4^{\circ} \mathrm{C}$ to produce a clear protein solution. For quantification of proteins, the BCA colorimetric test was performed. After protein quantification, a C4 reverse phase analytical column was used to separate the protein extracts. The linear portion of the gradient consisted of increasing buffer $\mathrm{B}$ (acetonitrile, $0.1 \%$ TFA) to buffer $\mathrm{A}$ (double distilled $\mathrm{H}_{2} \mathrm{O}, 0.1 \%$ TFA); $20-45 \%$ for the first $35 \mathrm{~min}$ and $\sim 70 \%$ for the next $15 \mathrm{~min}$. The fractions were collected every $30 \mathrm{sec}$ in a 96-well tube. These fractions were dried and redissolved in $70 \%$ ACN. MALDI-MS was performed to confirm whether proteins with the expected molecular weights were included following application of SA matrix to an aliquot of these fractions. Fractions containing $\mathrm{m} / \mathrm{z}$ values of interest were fur- 

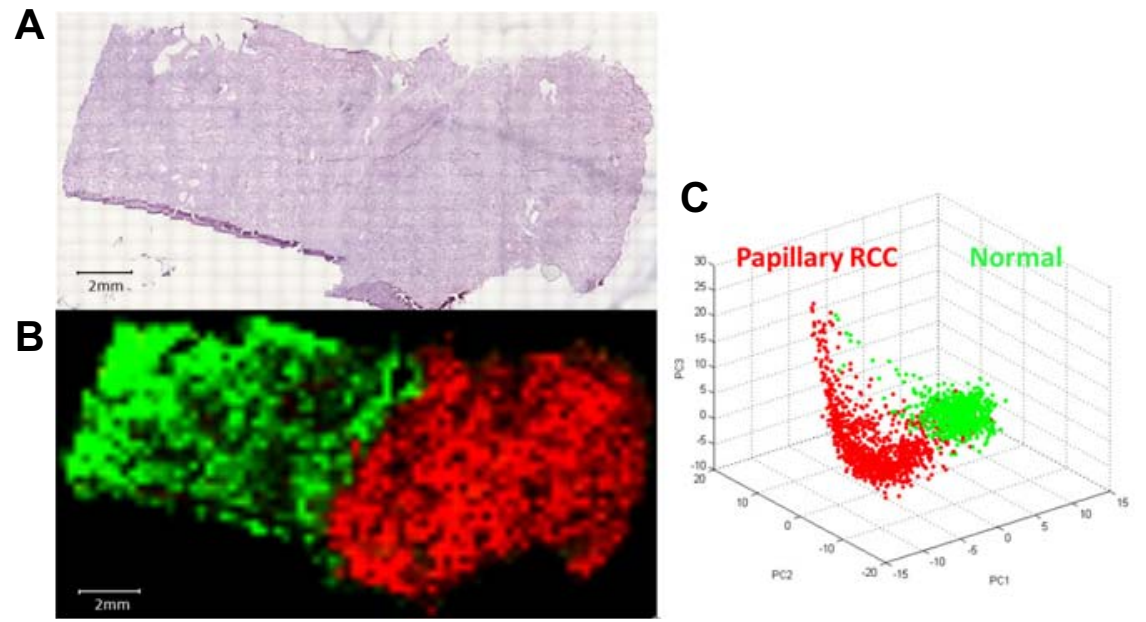

Fig. 1. MALDI-IMS from surgical papillary RCC tissue. Optical images of an H\&Estained section (A) and MALDI-IMS image (B) of a representative papillary $R C C$. Papillary RCC and normal regions were differentiated in surgical tissue by PCA (C). PCA was carried out with ClinPro Tools, and the image was displayed on Fleximaging. Normal and papillary RCC regions are displayed in green and red, respectively. Scale bar represents $2 \mathrm{~mm}$. ther separated using a C8 reverse phase analytical column under the same conditions. Fractions containing specific $\mathrm{m} / \mathrm{z}$ values of interest were separated by SDS-PAGE and then stained by the silver staining method. Bands that correlated with $\mathrm{m} / \mathrm{z}$ values of interest were excised and digested with trypsin.

The extracted tryptic peptides were analyzed using an LTQ mass spectrometer (Thermo Finnigan, USA) coupled with an Ultimate 3000 system (Dionex LC Packings, Idstein, Germany). Tryptic peptides were applied to a custom analytic column (75 $\mu \mathrm{m} \times 10 \mathrm{~cm})$ packed with regular $\mathrm{C} 18$ resin $(5 \mu \mathrm{m}$ particle size $)$ in the presence of solvent $A(5 \% \mathrm{ACN}, 0.1 \%$ formic acid). Samples were resolved using a linear gradient of solvent B ( $100 \%$ ACN, $0.1 \%$ formic acid); $5-60 \%$ over $60 \mathrm{~min}, 60-90 \%$ over $10 \mathrm{~min}$ at a flow rate of $0.2 \mu \mathrm{l} / \mathrm{min}$. The separated peptide ions eluted from the analytic column were entered into the mass spectrometer with an electrospray voltage of $2.1 \mathrm{kV}$. All MS/MS spectra were acquired in data-dependent mode for fragmentation of the five most abundant peaks from the full MS scan with $35 \%$ normalized collision energy. The dynamic exclusion duration was $180 \mathrm{~s}$, exclusion mass width was $1.5 \mathrm{Da}$, list of dynamic exclusion was 50 , ion selection threshold was 250 counts, and an activation $Q$-value of 0.25 was used.

The acquired MS/MS spectra were generated by Extractmsn v4.0 and searched against the Human IPI protein database (ipi.Human.v3.58, http://www.ebi.ac.uk/IPI/, 79,794 protein sequence entries) with TurboSEQUEST v.27 (Thermo Finnigan, USA) using the following search parameters: enzyme specificity/trypsin, precursor ion mass tolerances of \pm 2 Thomson (Th) and fragment ion mass tolerances $\pm 1 \mathrm{Th}$, number of missed cleavage sites of 2 , and oxidation on Met (+ $16 \mathrm{Da})$ as variable modification. After computation of the search, we validated MS/MS-based peptide and protein identification using Scaffold 2 (Proteome Software, USA), which is based on probability thresholds. We obtained a list of peptides that were established at greater than $95 \%$ probability according to the Peptide Prophet Algorithm (Keller et al., 2002). When at least two unique peptides are used, peptide identification with Protein Prophet is reliable with $99 \%$ confidence.

Immunohistochemistry of surgical tissues and TMAs Immunohistochemical staining for S100A11 and ferritin light chain was performed after cutting the paraffin block of the correspond- ing tumor tissue to a thickness of $4 \mu \mathrm{m}$. All immunohistochemistry was carried out using avidin-biotin in an autoimmunostainer (Ventana, USA). Rabbit polyclonal anti-ferritin light chain antibody (Abcam, USA, ab69089) and monoclonal anti-S100A11 antibody (Sigma, USA, WH0006282M1-100UG) were used for staining.

\section{RESULTS}

Cancerous and normal regions were distinguished by MALDI-IMS

To distinguish cancerous regions from normal regions, principal component analysis (PCA) was carried out with whole MALDIIMS data using ClinPro Tools and Fleximaging software. MALDI images after PCA and H\&E stains are displayed in Figs. $1 \mathrm{~A}$ and $1 \mathrm{~B}$, respectively. The results of $\mathrm{PCA}$ indicate that there was a clear difference in the profiles of protein species between normal and RCC regions ( $p<0.001$ ) (Fig. 1C). PCA also showed good correlation with the results from histological analysis.

\section{Presence of peaks with regional expression}

To identify the set of molecular ions that differentiated papillary RCC from normal kidney, we compared the average spectra from cancerous and normal regions in surgical cancer tissues (Fig. 2). Among 23 differentially expressed peaks showing an at least 1.5-fold difference, 15 and 8 peaks were upregulated in papillary RCC and normal regions, respectively. In papillary RCC regions, the upregulated peaks were detected over a broad range of $\mathrm{m} / \mathrm{z}$ values (3600-19000) as following: $\mathrm{m} / \mathrm{z} 3600$, $\mathrm{m} / \mathrm{z} 4177, \mathrm{~m} / \mathrm{z}$ 5703, m/z 6675, m/z 6928, m/z 7040, m/z 7166, $\mathrm{m} / \mathrm{z}$ 7437, $\mathrm{m} / \mathrm{z}$ 7505, m/z 7835, m/z 9747, m/z 11182, m/z $11671, \mathrm{~m} / \mathrm{z} 18779$, and $\mathrm{m} / \mathrm{z}$ 19921. In normal regions, several peaks were detected over an $\mathrm{m} / \mathrm{z}$ range of 5000-10500 including $\mathrm{m} / \mathrm{z} 5513, \mathrm{~m} / \mathrm{z}$ 8457, m/z 8585, m/z 8872, m/z 9082, m/z 10043, m/z 10101, and m/z 10259. As m/z 11671 and $\mathrm{m} / \mathrm{z}$ 19921 showed a statistically significant difference $(p<0.05)$, further analysis for protein identification was performed.

Identification of S100A11 and ferritin light chain

To identify the differentially expressed proteins in papillary RCC, proteins were extracted from tissue lumps after sectioning for imaging. The protein extracts were fractionated according to hydrophobicity via reverse phase HPLC. After BCA quantifica- 

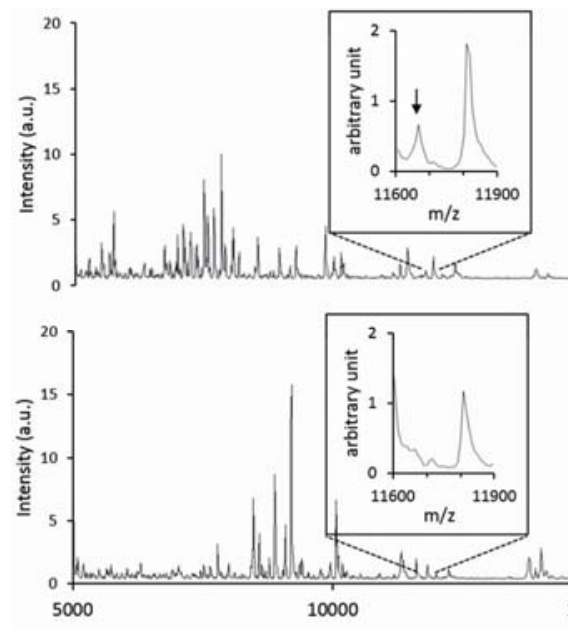

15000

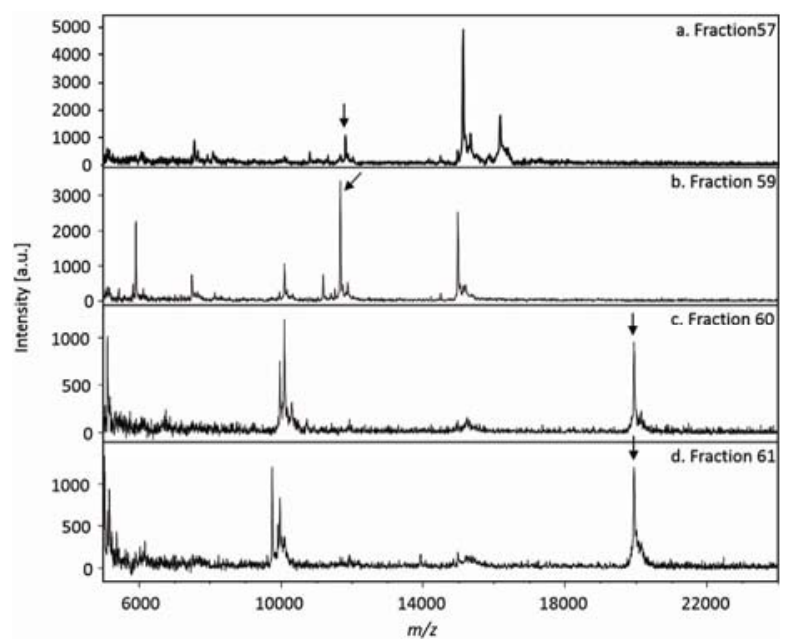

Fig. 3. MALDI MS protein profiles of HPLC fractions containing the proteins of interest. After separation of extracted proteins from tissue lumps using a C4 reverse phase HPLC column, fraction 10 of the C4 separation was further separated with a C8 reverse phase HPLC column. Each fraction was subjected to MALDI MS to identify fractions with mass signals of interest. Fractions with the target proteins of $12 \mathrm{kDa}(\mathrm{A}, \mathrm{B})$ and $20 \mathrm{kDa}(\mathrm{C}, \mathrm{D})$ were pooled for further protein identification. The peaks marked with arrows correspond to the target proteins.

tion, $3 \mathrm{mg}$ of protein was loaded onto a C4 reverse phase liquid chromatography column for fractionation into 12 fractions. Each fraction was analyzed with MALDI-TOF to confirm whether the differentially expressed proteins with selected $\mathrm{m} / \mathrm{z}$ values from MALDI-IMS were included in the fraction. Among the differentially expressed peaks in papillary RCC, two proteins with molecular weights of approximately $12 \mathrm{kDa}$ and $20 \mathrm{kDa}$ were selected for identification, as they were unique to cancerous regions, abundant, and reproducible in the analyzed tissues $(\mathrm{n}=$ 3). The fractions containing proteins of $12 \mathrm{kDa}$ and $20 \mathrm{kDa}$ were further separated by C8 reverse phase liquid column chromatography. A total of 100 fractions were collected. Fractions containing the target $\mathrm{m} / \mathrm{z}$ values that were differentially expressed in papillary RCC regions were selected for further protein identification and separated by SDS-PAGE. The protein bands corresponding to the molecular weights of the selected peaks were excised and subjected to LC-ESI-MS/MS following trypsin digestion. After correlation of acquired MS/MS spectra with the human protein database using the database-searching program, SEQUEST, S100A11 was identified in fractions 57 and 59, and ferritin light chain was identified in fractions 60 and 61 (Fig. 3). The representative MS/MS spectra of peptides from S100A11 and ferritin light chain are shown in Fig. 4. Ion images corresponding to the proteins within the surgical tissues of papillary RCC are displayed in Fig. 5. Specific localization of the proteins to the cancerous regions of papillary RCC was apparent. Molecular images of the ions at m/z 11671 and 19949 indicated enrichment of these molecular species in RCC regions (Figs. 5A and 5B). As an additional validation measure, we performed immunohistochemistry for S100A11 and ferritin light chain, the results of which supported MALDI-IMS results (Figs. 5C and 5D). The immunohistochemistry results clearly showed that S100A11 and ferritin light chain were overexpressed in tumor cells and not the surrounding normal tissue.

\section{DISCUSSION}

Identification of proteins that are specific for papillary RCC may be useful for the diagnosis and treatment of the disease. In this report, papillary RCC tissues were analyzed by MALDI-IMS and LC-MS/MS in order to identify protein markers specific for papillary RCC region compared to the adjacent normal region. Since conventional proteomics approaches for the identification of proteins specific for RCC do not provide spatial information (Unwin et al., 2003), focal distribution of marker proteins cannot be observed. On the contrary, for proteomic analysis with MALDI-IMS, focal distribution can be observed and confirmed by immunohistochemistry (Morgan et al., 2013). Furthermore, when RCC has a more complex structure and obscure boundary, spatial information provided by MALDI-IMS will have more merit (Morgan et al., 2013). In the present study, protein signatures obtained by MALDI-IMS clearly identified boundaries confirmed by PCA. Since PCA uses statistical methods to identify peaks that have differential distribution, papillary RCC regions can be easily discriminated from normal regions. The results of current study suggest that PCA can be used for the selection of 
A
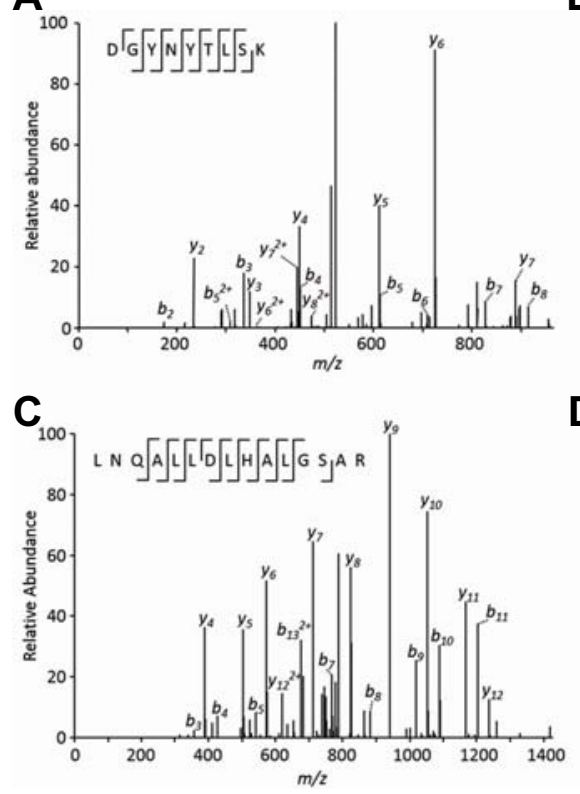

B

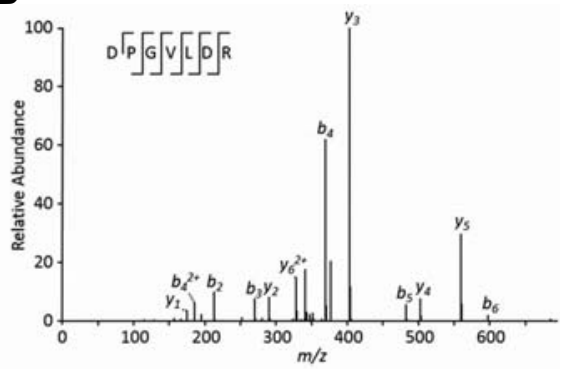

D

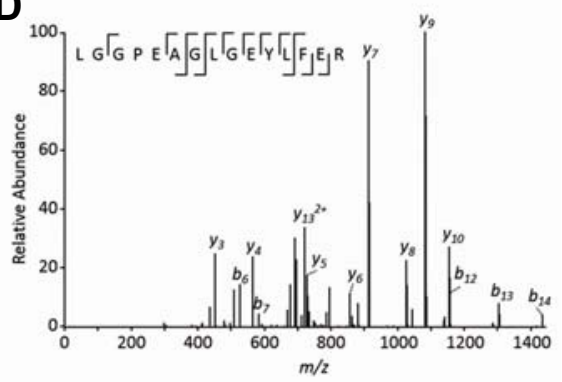

Fig. 4. Representative MS/MS spectra of S100A11 and ferritin light chain. (A) DGYNYTLSK, (B) DPGVLDR of S100A11, (C) LNQALLDLHALGSAR, and (D) LGGPEAGLGEYLFER of ferritin light chain
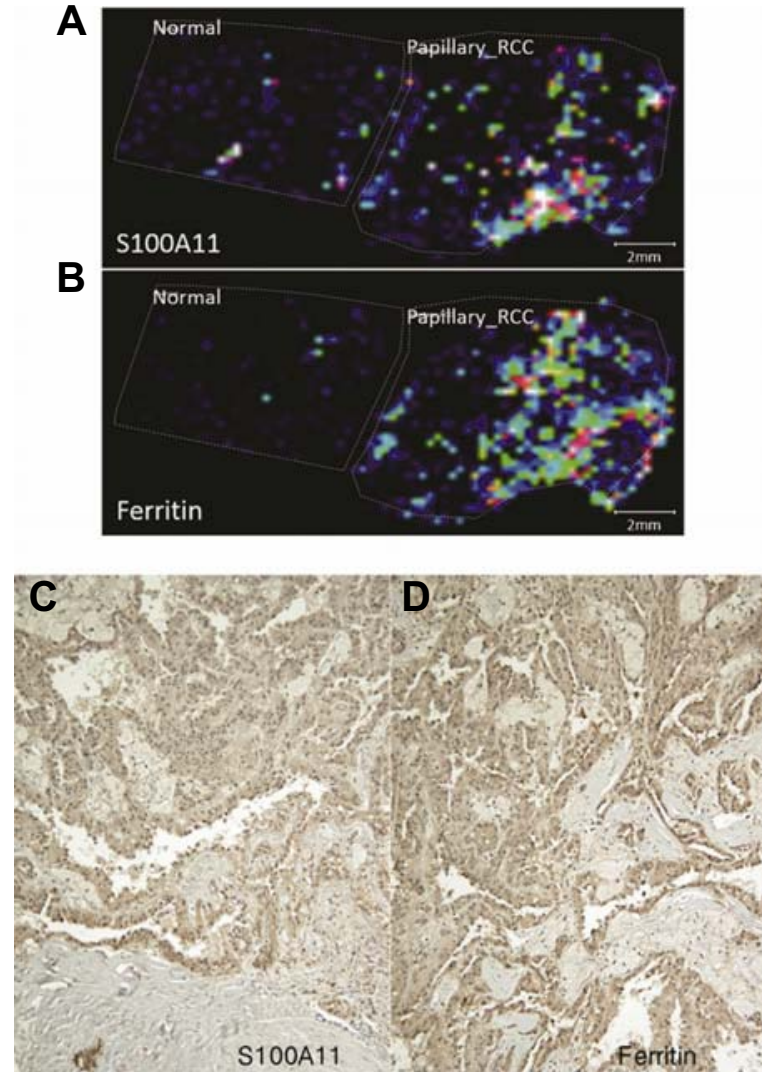

Fig. 5. Distribution of proteins identified in tissues. Identified protein images from the analysis of surgical tissue sections including normal and papillary RCC regions were generated by MALDI-IMS and immunohistochemical staining for papillary RCC (200X). MALDI imaging $(A, B)$ and $\mathrm{IHC}(\mathrm{C}, \mathrm{D})$ of human S100A11 $(\mathrm{A}, \mathrm{C})$ and ferritin light chain $(B, D)$ revealed increased expression of $S 100 A 11$ and ferritin light chain in RCC regions. peaks that have differential distribution. However, peaks with lower $\mathrm{m} / \mathrm{z}$ values may exhibit stronger intensities compared to peaks with higher $\mathrm{m} / \mathrm{z}$ values; therefore, there may be a preference for peaks with lower $\mathrm{m} / \mathrm{z}$ values in the selection of principal components. Hence, the selection of peaks with differential distribution was performed manually with the help of PCA.

Most of the differentially expressed peaks were selected by comparing peak profiles between cancer and normal regions of surgical papillary RCC samples, and their distribution was confirmed with MALDI-IMS. Identification of proteins in situ following on tissue trypsin digestion provides more valuable information than sequential analysis of MALDI-IMS and LC-MS/MS (Morgan et al., 2013). However, due to the low ionization efficiency of peptides from tissue after in situ tryptic digestion, we performed protein identification by LC-MS/MS following fractionation of proteins with HPLC after protein extraction from the target tissue in this study. To increase the resolution of separation, proteins were separated with a $\mathrm{C} 4$ reverse phase column. After analyzing fractions containing proteins of interest by MALDI-TOF, a C8 reverse phase column was subsequently used for further separation. Through this extensive fractionation, S100A11 and ferritin light chain were identified as differentially expressed proteins in cancerous regions. The distribution of molecular ion peaks corresponding to S100A11 and ferritin light chain was enriched in papillary RCC regions. Immunohistochemical staining of these proteins confirmed that the distribution of S100A11 and ferritin light chain was much more abundant in papillary RCC regions compared to normal tissue.

S100A proteins are encoded by one family of epidermal differentiation complex (EDC) genes. Recent study showed that the expression of EDC genes was heterogeneous (Tyszkiewicz et al., 2014) : expression of genes corresponding to S100A1 and S100A4 was significantly down-regulated in oral cancer compared to normal mucosa; expression of S100A11, S100A7, S100A3 and S100A2 was up-regulated in head and neck cancers. Although the utility of S100 proteins in RCC has not been widely investigated, recent studies showed expression of S100A1 in renal tubules and renal cell neoplasms (Rocca et al., 
2007; Tyszkiewicz et al., 2014). Overexpression of S100A1 and S100A4 in various types of renal cell neoplasms was validated by both immunohistochemical detection and RT-PCR analysis in clear cell RCC (Rocca et al., 2007; Yang et al., 2012) , papillary RCC (Rocca et al., 2007) and oncocytomas. Although the overexpression of S100A11 protein has been shown in various tumors including colorectum (Stulik et al., 1999), uterine smooth muscle (Kanamori et al., 2004), thyroid (Torres-Cabala et al., 2004), the overexpression of S100A11 protein in RCC has not been reported. In this study, we found that S100A11 protein and ferritin light chain are expressed in papillary RCC. We found significant differences in expression levels of S100A11 and ferritin light chain between tumor region and the adjacent normal region, which suggests that S100A11 and ferritin light chain could be useful biomarkers for selective detection of papillary RCC. The combined examination of these molecules might be useful in differential diagnosis in RCC cancer cases.

In conclusion, we identified overexpressed proteins, S100A11 and ferritin light chain, in tumor regions of papillary RCC by the use of MALDI-IMS and LC-MS/MS and subsequently confirmed the protein signatures that distinguish papillary RCC from the adjacent normal regions by $\mathrm{IHC}$.

\section{ACKNOWLEDGMENTS}

This work was financially supported by the Bio- and Medical Technology Development Program (Project No. 2012M3A9B 6055305 through the National Research Foundation of Korea funded by the Ministry of Science, ICT and Future Planning.

\section{REFERENCES}

Andersson, M., Groseclose, M.R., Deutch, A.Y., and Caprioli, R.M (2008). Imaging mass spectrometry of proteins and peptides: 3D volume reconstruction. Nat. Methods 5, 101-108.

Bosso, N., Chinello, C., Picozzi, S.C., Gianazza, E., Mainini, V., Galbusera, C., Raimondo, F., Perego, R., Casellato, S., Rocco, F., et al. (2008). Human urine biomarkers of renal cell carcinoma evaluated by ClinProt. Proteomics Clin. Appl. 2, 1036-1046.

Chaurand, P., Schwartz, S.A., and Caprioli, R.M. (2002). Imaging mass spectrometry: a new tool to investigate the spatial organization of peptides and proteins in mammalian tissue sections. Curr. Opin. Chem. Biol. 6, 676-681.

Chaurand, P., Schwartz, S.A., Reyzer, M.L., and Caprioli, R.M (2005). Imaging mass spectrometry: principles and potentials. Toxicol. Pathol. 33, 92-101.

Chaurand, P., Norris, J.L., Cornett, D.S., Mobley, J.A., and Caprioli, R.M. (2006). New developments in profiling and imaging of proteins from tissue sections by MALDI mass spectrometry. $\mathrm{J}$. Proteome Res. 5, 2889-2900.

Essen, A., Ozen, H., Ayhan, A., Ergen, A., Tasar, C., and Remzi, F. (1991). Serum ferritin: a tumor marker for renal cell carcinoma. J. Urol. 145, 1134-1137.

Francese, S., Dani, F.R., Traldi, P., Mastrobuoni, G., Pieraccini, G. and Moneti, G. (2009). MALDI mass spectrometry imaging, from its origins up to today: the state of the art. Comb. Chem. High Throughput Screen 12, 156-174.

Fuhrman, S.A., Lasky, L.C., and Limas, C. (1982). Prognostic significance of morphologic parameters in renal cell carcinoma. Am. J. Surg. Pathol. 6, 655-663.

Kanamori, T., Takakura, K., Mandai, M., Kariya, M., Fukuhara, K., Sakaguchi, M., Huh, N.H., Saito, K., Sakurai, T., Fujita, J., et al. (2004). Increased expression of calcium-binding protein $\mathrm{S} 100$ in human uterine smooth muscle tumours. Mol. Hum. Reprod.10, 735-742.

Keller, A., Nesvizhskii, A.I., Kolker, E., and Aebersold, R. (2002). Empirical statistical model to estimate the accuracy of peptide identifications made by MS/MS and database search. Anal. Chem. 74, 5383-5392.

Kirkali, Z., Guzelsoy, M., Mungan, M.U., Kirkali, G., and Yorukoglu, K (1999). Serum ferritin as a clinical marker for renal cell carcinoma: influence of tumor size and volume. Urol. Int. 62, 21-25.
Ljungberg, B. (2004). Prognostic factors in renal cell carcinoma Scand. J. Surg. 93, 118-125.

Miyata, Y., Koga, S., Nishikido, M., Hayashi, T., and Kanetake, H. (2001). Relationship between serum ferritin levels and tumour status in patients with renal cell carcinoma. BJU Int. 88, 974-977.

Morgan, T.M., Seeley, E.H., Fadare, O., Caprioli, R.M., and Clark, P.E. (2013). Imaging the clear cell renal cell carcinoma proteome. J. Urol. 189, 1097-1103.

Motzer, R.J., Bander, N.H., and Nanus, D.M. (1996). Renal-cell carcinoma. N Engl. J. Med. 335, 865-875.

Ohuchida, K., Mizumoto, K., Ohhashi, S., Yamaguchi, H., Konomi, H., Nagai, E., Yamaguchi, K., Tsuneyoshi, M., and Tanaka, M. (2006). S100A11, a putative tumor suppressor gene, is overexpressed in pancreatic carcinogenesis. Clin. Cancer Res. $12,5417-5422$.

Ozen, H., Uygur, C., Sahin, A., Tekgul, S., Ergen, A., and Remzi, D. (1995). Clinical significance of serum ferritin in patients with renal cell carcinoma. Urology 46, 494-498.

Rehman, I., Azzouzi, A.R., Cross, S.S., Deloulme, J.C., Catto, J.W. Wylde, N., Larre, S., Champigneuille, J., and Hamdy, F.C. (2004) Dysregulated expression of S100A11 (calgizzarin) in prostate cancer and precursor lesions. Hum. Pathol. 35, 1385-1391.

Rocca, P.C., Brunelli, M., Gobbo, S., Eccher, A., Bragantini, E., Mina, M.M., Ficarra, V., Zattoni, F., Zamo, A., Pea, M., et al. (2007). Diagnostic utility of S100A1 expression in renal cell neoplasms: an immunohistochemical and quantitative RT-PCR study. Mod. Pathol. 20, 722-728.

Seliger, B., Dressler, S.P., Lichtenfels, R., and Kellner, R. (2007). Candidate biomarkers in renal cell carcinoma. Proteomics 7 , 4601-4612.

Singh, K.J., Singh, S.K., Suri, A., Vijjan, V., Goswami, A.K., and Khullar, M. (2005). Serum ferritin in renal cell carcinoma: effect of tumor size, volume grade, and stage. Indian J. Cancer 42, 197-200.

Siu, K.W., DeSouza, L.V., Scorilas, A., Romaschin, A.D., Honey, R.J., Stewart, R., Pace, K., Youssef, Y., Chow, T.F., and Yousef, G.M. (2009). Differential protein expressions in renal cell carcinoma: new biomarker discovery by mass spectrometry. J. Proteome Res. 8, 3797-3807.

Steurer, S., Seddiqi, A.S., Singer, J.M., Bahar, A.S., Eichelberg, C., Rink, M., Dahlem, R., Huland, H., Sauter, G., Simon, R., et al. (2014). MALDI imaging on tissue microarrays identifies molecular features associated with renal cell cancer phenotype. Anticancer Res. 34, 2255-2261.

Stoeckli, M., Chaurand, P., Hallahan, D.E., and Caprioli, R.M. (2001). Imaging mass spectrometry: a new technology for the analysis of protein expression in mammalian tissues. Nat. Med. 7, 493-496.

Stulik, J., Koupilova, K., Osterreicher, J., Knizek, J., Macela, A., Bures, J., Jandik, P., Langr, F., Dedic, K., and Jungblut, P.R (1999). Protein abundance alterations in matched sets of macroscopically normal colon mucosa and colorectal carcinoma. Electrophoresis 20, 3638-3646.

Torres-Cabala, C., Panizo-Santos, A., Krutzsch, H.C., Barazi, H. Namba, M., Sakaguchi, M., Roberts, D.D., and Merino, M.J. (2004). Differential expression of S100C in thyroid lesions. Int. J. Surg. Pathol. 12, 107-115.

Tyszkiewicz, T., Jarzab, M., Szymczyk, C., Kowal, M., Krajewska, J., Jaworska, M., Fraczek, M., Krajewska, A., Hadas, E., Swierniak, M., et al. (2014). Epidermal differentiation complex (locus 1q21) gene expression in head and neck cancer and normal mucosa. Folia Histochem. Cytobiol. 52, 79-89.

Unwin, R.D., Craven, R.A., Harnden, P., Hanrahan, S., Totty, N., Knowles, M., Eardley, I., Selby, P.J., and Banks, R.E. (2003). Proteomic changes in renal cancer and co-ordinate demonstration of both the glycolytic and mitochondrial aspects of the Warburg effect. Proteomics 3, 1620-1632.

Wang, G., Wang, X., Wang, S., Song, H., Sun, H., Yuan, W., Cao B., Bai, J., and Fu, S. (2008). Colorectal cancer progression correlates with upregulation of S100A11 expression in tumor tissues. Int. J. Colorectal. Dis. 23, 675-682.

Yang, H., Zhao, K., Yu, Q., Wang, X., Song, Y., and Li, R. (2012). Evaluation of plasma and tissue S100A4 protein and mRNA levels as potential markers of metastasis and prognosis in clear cell renal cell carcinoma. J. Int. Med. Res. 40, 475-485. 